University of South Florida

DIGITAL COMMONS

Digital Commons @ University of

@ UNIVERSITY OF SOUTH FLORIDA

South Florida

School of Geosciences Faculty and Staff

Publications

School of Geosciences

6-2015

\title{
Multiscale Postseismic Behavior on a Megathrust: The 2012 Nicoya Earthquake, Costa Rica
}

\author{
Rocco Malservisi \\ University of South Florida, rocco@usf.edu \\ Susan Y. Schwartz \\ University of California, Santa Cruz \\ Nicholas Voss \\ University of South Florida, nvoss@mail.usf.edu \\ Marino Protti \\ Observatorio Vulcanologico y Sismologico de Costa Rica \\ Victor Gonzalez \\ Observatorio Vulcanologico y Sismologico de Costa Rica
}

See next page for additional authors

Follow this and additional works at: https://digitalcommons.usf.edu/geo_facpub

Part of the Earth Sciences Commons

\section{Scholar Commons Citation}

Malservisi, Rocco; Schwartz, Susan Y.; Voss, Nicholas; Protti, Marino; Gonzalez, Victor; Dixon, Timothy H.; Jiang, Yan; Newman, Andrew V.; Richardson, Jacob; Walter, Jacob I.; and Voyenko, Denis, "Multiscale Postseismic Behavior on a Megathrust: The 2012 Nicoya Earthquake, Costa Rica" (2015). School of Geosciences Faculty and Staff Publications. 1530.

https://digitalcommons.usf.edu/geo_facpub/1530

This Article is brought to you for free and open access by the School of Geosciences at Digital Commons @ University of South Florida. It has been accepted for inclusion in School of Geosciences Faculty and Staff Publications by an authorized administrator of Digital Commons @ University of South Florida. For more information, please contact digitalcommons@usf.edu. 


\section{Authors}

Rocco Malservisi, Susan Y. Schwartz, Nicholas Voss, Marino Protti, Victor Gonzalez, Timothy H. Dixon, Yan Jiang, Andrew V. Newman, Jacob Richardson, Jacob I. Walter, and Denis Voyenko 


\section{Geochemistry, Geophysics, Geosystems}

\section{RESEARCH ARTICLE \\ 10.1002/2015GC005794 \\ Multiscale postseismic behavior on a megathrust: The 2012 Nicoya earthquake, Costa Rica}

Key Points:

- Significant afterslip occurs within $3 \mathrm{~h}$ of main event

- Postseismic relaxation is observed to have three characteristic times - Afterslip and seismic zones are not colocated with slow slip events

\section{Correspondence to:}

R. Malservisi,

rocco@usf.edu

Citation:

Malservisi, R., et al. (2015), Multiscale postseismic behavior on a megathrust: The 2012 Nicoya earthquake, Costa Rica, Geochem. Geophys. Geosyst., 16, 1848-1864, doi:10.1002/ $2015 \mathrm{GC} 005794$

Received 2 MAR 2015

Accepted 23 MAY 2015

Accepted article online 28 MAY 2015

Published online 17 JUN 2015

\author{
Rocco Malservisi ${ }^{1}$, Susan Y. Schwartz ${ }^{2}$, Nicholas Voss ${ }^{1}$, Marino Protti ${ }^{3}$, Victor Gonzalez ${ }^{3}$, \\ Timothy H. Dixon', Yan Jiang ${ }^{4}$, Andy V. Newman', Jacob Richardson', Jacob I. Walter6, \\ and Denis Voyenko'
}

${ }^{1}$ School of Geosciences, University of South Florida, Tampa, Florida, USA, ${ }^{2}$ Department of Earth and Planetary Science, University of California, Santa Cruz, California, USA, ${ }^{3}$ Observatorio Vulcanológico y Sismológico de Costa Rica, Universidad Nacional, Heredia, Costa Rica, ${ }^{4}$ Pacific Geoscience Centre, Geological Survey of Canada, Sidney, British Columbia, Canada, ${ }^{5}$ School of Earth and Atmospheric Sciences, Georgia Institute of Technology, Atlanta, Georgia, USA, ${ }^{6}$ Institute for Geophysics, University of Texas at Austin, Austin, Texas, USA occurred beneath a dense network of continuous GPS and seismic stations. Many of the GPS stations
(C) 2015. American Geophysical Union. All Rights Reserved.
Abstract The Nicoya Peninsula in northwest Costa Rica overlies a section of the subduction megathrust along the Middle America Trench. On 5 September 2012, a moment magnitude 7.6 megathrust earthquake recorded the event at high rate, $1 \mathrm{~Hz}$ or better. We analyze the temporal and spatial evolution of surface deformation after the earthquake. Our results show that the main rupture was followed by significant afterslip within the first $3 \mathrm{~h}$ following the main event. The behavior of the surface displacement can be represented by relaxation processes with three characteristic times: 7, 70, and more than 400 days. We assume that the long relaxation time corresponds to viscoelastic relaxation and the intermediate relaxation time corresponds to afterslip on the main fault. The short relaxation time may represent a combination of rapid afterslip, poroelastic adjustment in the upper crust, or other processes. During the first few months that followed the earthquake, afterslip likely released a significant amount of slip deficit still present following the coseismic rupture, in particular updip of the rupture. Afterslip seems to be bounded updip by regions affected by slow slip events prior to the earthquake, suggesting that the two processes are influenced by different frictional properties.

\section{Introduction}

Surface displacements in the days, months, and years following large earthquakes can be sensitive probes of frictional conditions on the fault interface and rheology of the nearby crust and upper mantle. For subduction zone megathrusts, often producing Earth's largest earthquakes and most tsunami, these studies can be challenging, as critical areas undergoing seismic rupture and postseismic motion usually lie far offshore, where on-land instrumentation lacks sensitivity. Here we report new geodetic data for 2 years following the $M_{w} 7.65$ September 2012 Nicoya, Costa Rica earthquake. At this location (Figure 1), the Nicoya Peninsula extends within $60 \mathrm{~km}$ of the trench, and seismic rupture occurred immediately under the peninsula, allowing geodetic measurements that are sensitive to a range of postseismic motions. Geodetic data reveal significant postseismic motion within a few hours of the main seismic rupture and during a $M_{w} 6.5$ aftershock. We also observe a possible separate slow slip event in February 2014 ( 1.4 years after the 2012 earthquake). Analysis of the data shows the presence of three distinct time constants for the overall exponential decay of postseismic motion that we believe is related to three distinct processes. The combination of afterslip, aftershocks, and preearthquake slow slip constitute a significant fraction of the overall strain budget, indicating that most of the accumulated moment due to plate motion is released by processes other than megathrust earthquakes, including aseismic processes.

\subsection{Geologic and Seismic Background}

The Nicoya Peninsula forms the western edge of the Caribbean plate, where the Cocos plate subducts beneath the Caribbean plate along the Middle American trench at about $8 \mathrm{~cm} / \mathrm{yr}$ [DeMets, 2001, DeMets et al., 2010] (Figure 1). The region has a well-defined earthquake cycle, with large ( $M>7$ ) earthquakes in 1853, 1900, 1950 (M 7.7), and most recently 5 September $2012\left(M_{w}\right.$ 7.6). Smaller $(M \sim 7)$ events in 1978 and 1990 


\section{QAGU Geochemistry, Geophysics, Geosystems}
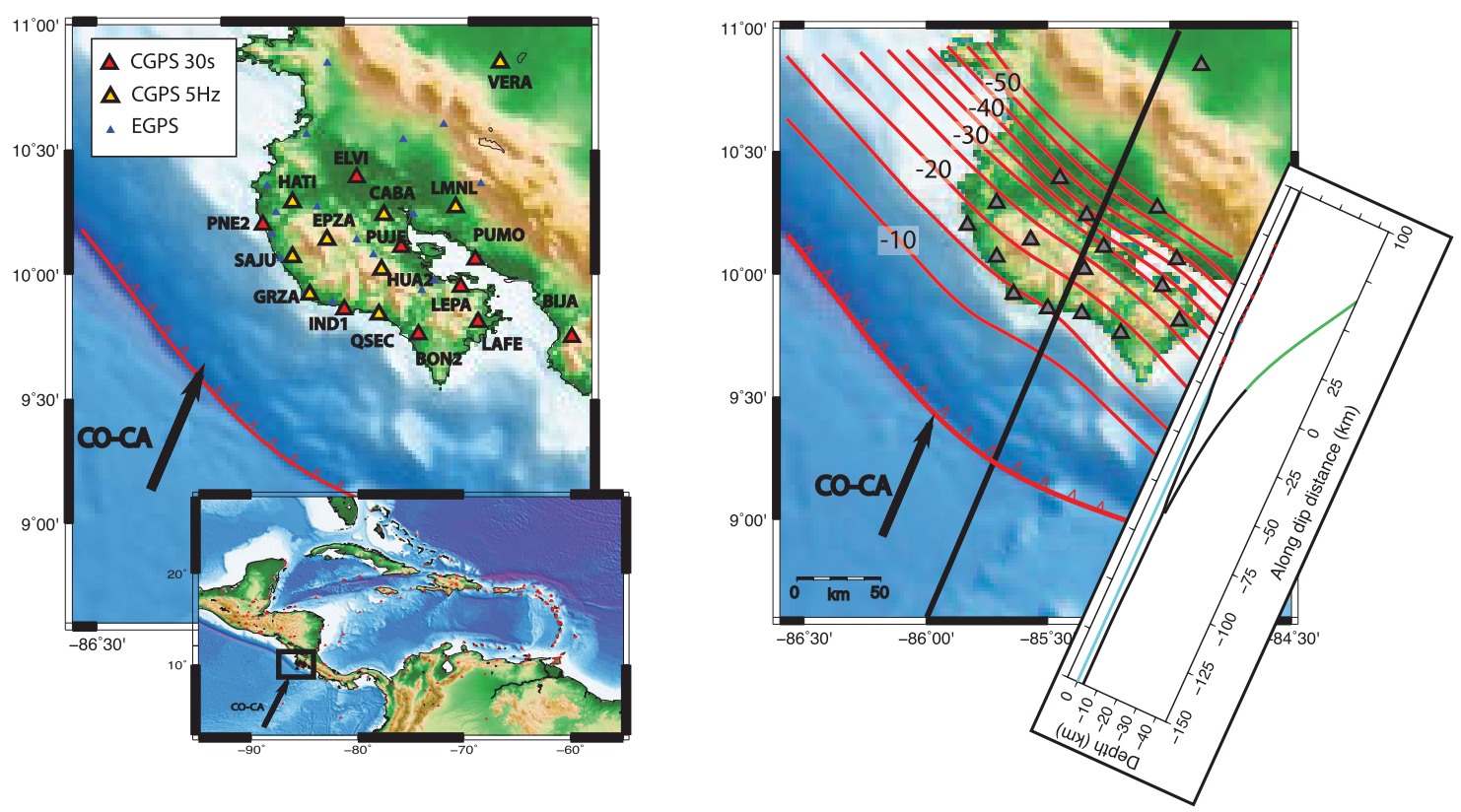

Figure 1. (left) Location of the study area showing the position of the GPS stations used in this study. Cocos-Caribbean plate relative velocity from MORVEL [DeMets et al., 2010]. (right) Position of the network with respect to the subducting slab (slab contour from DeShon et al. [2006]). Yellow triangles indicate GPSs that recorded at high rate during the September 2012 earthquake. The seismogenic zone (green line in the cross section) is located underneath the geodetic network (red dots in cross section).

have also occurred nearby [Protti et al., 1995]. Large tsunamis have not been reported for any of these events [Chacón-Barrantes and Protti, 2011] but the $1992 \mathrm{M}_{\mathrm{w}} 7.6$ Nicaragua earthquake, $150 \mathrm{~km}$ to the northwest, generated a large tsunami, reflecting shallow rupture [Satake, 1994; Kikuchi and Kanamori, 1995]. Slow slip events are common in the region [Outerbridge et al., 2010; Jiang et al., 2012; Walter et al., 2013]. These enigmatic events have now been identified in many subduction zones [Schwartz and Rokosky, 2007; Beroza and Ide, 2011], and represent largely aseismic slip on the plate boundary lasting weeks, months, or years [Brodsky and Mori, 2007]. In terms of their rupture speed and duration, they are similar to afterslip, and we explore some consequences of that similarity here. An analysis of preearthquake slow slip in Costa Rica is presented in Dixon et al. [2014].

Surface displacements associated with the 5 September 2012 M 7.6 Nicoya earthquake are reported in Protti et al. [2014]. These authors showed that seismic rupture occurred mainly on a patch of the plate interface below the peninsula that was locked for more than two decades prior to the 2012 event [Dixon, 1993; Feng et al., 2012]. Analysis of seismological data for the earthquake is presented in Yue et al. [2013]. These authors showed that rupture initiated just offshore then proceeded downdip and to the northeast. Their analysis included strong motion data, teleseismic waves, and high rate GPS data from a subset of our network that recorded displacement at 1 or $5 \mathrm{~Hz}$. Here we use the same GPS instrumentation to investigate motions in the first few hours after the event. The earthquake did not produce a significant tsunami and did not have significant offshore rupture, even though measurements prior to the earthquake suggested significant offshore strain accumulation [Feng et al., 2012]. Shallow slow slip events in the offshore region released some but not all of the accumulated strain in the decade leading up to the earthquake [Dixon et al., 2014], thus it is of interest to investigate the possible role of afterslip in releasing any residual offshore strain.

\section{Data Analysis}

Between 2002 and 2006, a network of 18 continuously recording GPS systems (CGPS) was installed on the Nicoya Peninsula to monitor strain accumulation, slow slip events and eventually observe a megathrust earthquake. The instruments recorded data at rates between one sample per $15 \mathrm{~s}$ and $5 \mathrm{~Hz}$. The data files were periodically downloaded by the Observatorio Vulcanologico y Sismologico de Costa Rica (OVSICORI) 


\begin{tabular}{|c|c|c|c|c|c|c|c|}
\hline Station & Lat & Lon & $\begin{array}{c}\text { First } \\
\text { Observation }\end{array}$ & $\begin{array}{l}\text { Number } \\
\text { of Obs. } \\
\text { (days) }\end{array}$ & $\begin{array}{l}\text { \% Complet. } \\
\text { Since } \\
5 \text { September } \\
2012\end{array}$ & $\begin{array}{c}\text { Rec. High } \\
\text { Rate on } \\
5 \text { September }\end{array}$ & UNAVCO Doi \\
\hline BIJA & 9.74 & -85.58 & 2009.6372 & 995 & 37.50 & & 10.7283/T5C53J0Q \\
\hline BON2 & 9.76 & -85.20 & 2004.7858 & 2761 & 98.63 & & 10.7283/T5W66HXJ \\
\hline CABA & 10.24 & -85.34 & 2009.5058 & 1638 & 86.81 & $\checkmark$ & 10.7283/T5GX48QQ \\
\hline ELVI & 10.39 & -85.45 & 2007.3265 & 2011 & 56.73 & & 10.7283/T59C6VKN \\
\hline EPZA & 10.14 & -85.57 & 2009.4976 & 1703 & 83.79 & $\square$ & $10.7283 / \mathrm{T} 5 \mathrm{JW} 8 \mathrm{C} 1 \mathrm{~S}$ \\
\hline GRZA & 9.92 & -85.63 & 2006.3326 & 2105 & 75.27 & & 10.7283/T5HX19V3 \\
\hline HATI & 10.29 & -85.71 & 2006.4504 & 2155 & 11.13 & $\square$ & 10.7283/T5X34VM5 \\
\hline HUA2 & 10.02 & -85.35 & 2002.7269 & 3553 & 83.38 & & 10.7283/T5RF5S67 \\
\hline IND1 & 9.86 & -85.50 & 2002.5626 & 3857 & 94.64 & & 10.7283/T58C9TDT \\
\hline LAFE & 9.81 & -84.96 & 2009.5113 & 1723 & 96.02 & & 10.7283/T57D2S80 \\
\hline LEPA & 9.95 & -85.03 & 2006.3107 & 2511 & 87.36 & & 10.7283/T5NP22M8 \\
\hline LMNL & 10.27 & -85.05 & 2007.3347 & 2660 & 97.94 & $\square$ & 10.7283/T51V5C3J \\
\hline PNE2 & 10.20 & -85.82 & 2009.5277 & 1205 & 94.64 & & 10.7283/T5D50K43 \\
\hline PUJE & 10.11 & -85.83 & 2002.7570 & 3182 & 21.57 & $\square$ & 10.7283/T54M92PG \\
\hline PUMO & 10.06 & -84.97 & 2007.3128 & 2509 & 95.74 & $\square$ & 10.7283/T55M63V9 \\
\hline QSEC & 9.84 & -85.36 & 2006.3217 & 2342 & 34.75 & $\square$ & 10.7283/T5SF2TBM \\
\hline SAJU & 10.07 & -85.71 & 2008.2382 & 2249 & 87.23 & $\square$ & 10.7283/T5F47M9C \\
\hline VERA & 10.85 & -84.87 & 2009.6454 & 1773 & 98.08 & $\square$ & 10.7283/T5MP51FF \\
\hline
\end{tabular}

and stored at the UNAVCO archive (www.unavco.org). Eight of the instruments (Figure 1 and Table 1) recorded at high rate $(1-5 \mathrm{~Hz})$ during the 5 September 2012 earthquake.

We analyzed all available data from the CGPS network from the time of installation to September 2014. For each station, static daily average positions were calculated. In addition, for the day of the mainshock (5 September), we derived a higher rate time series to investigate the temporal evolution of surface deformation at high resolution following the earthquake [Larson and Miyazaki, 2008].

All data were processed with GIPSY-OASIS 6.2 software, with orbits and satellite clock estimates provided by the Jet Propulsion Laboratory (JPL). Daily static positions were derived using the precise point positioning (PPP) method [Zumberge et al., 1997]. Phase ambiguity resolution was performed using the single receiver algorithm [Bertiger et al., 2010]. Ocean-loading effects were corrected using FES2004 [Lyard et al. 2006] (http://holt.oso.chalmers.se/loading/). VMF1 mapping functions were used for tropospheric delay [Boehm et al., 2006]. The daily solutions were then aligned with IGb08 [Rebischung et al., 2012] through the daily seven-parameters transformation ( $x$-files) provided by JPL. The time series were then corrected for offsets related to known equipment changes, other jumps from a visual inspection of the time series, and for the surface deformation induced by the slow slip events (SSEs) identified by Jiang et al. [2012]. The time series were detrended by removing the long-term linear trend, representing the interseismic velocity, and annual and semiannual signals, estimated by fitting the time series before 4 September.

For the $6 \mathrm{~h}$ following the earthquake of 5 September, we also evaluated the site positions at high time resolution using the high rate data and standard kinematic processing procedures of GIPSY-OASIS. We limit our study to the displacement observed after the passage of the seismic waves (typically 1-2 min duration) using techniques described in Larson and Miyazaki [2008] who utilized random walk filtering for analysis of high rate data.

Troposphere effects can be a major problem in GPS high rate data. To limit this problem, tropospheric delays were estimated by solving for two static positions, $6 \mathrm{~h}$ before the event and from 2 min after the earthquake. The site position following the mainshock was then estimated by fixing the computed tropospheric delay and applying a Kalman filter to estimate the antenna position, assuming a random walk with standard deviation set to $1 \times 10^{-8} \mathrm{~km} / \sqrt{ } \mathrm{s}$ [Larson and Miyazaki, 2008]. The resulting position estimate was then utilized as a nominal position for further estimation of the tropospheric delay in a static mode, iterating until no significant changes were observed (in general two iterations were sufficient). To limit computational time, $5 \mathrm{~s}$ average positions were estimated for the first $90 \mathrm{~min}$ after the earthquake and $300 \mathrm{~s}$ averages thereafter. Following Larson et al. [2007], we corrected the time series to minimize geometrical and multipath influences, using the average position of the previous five sidereal days. 

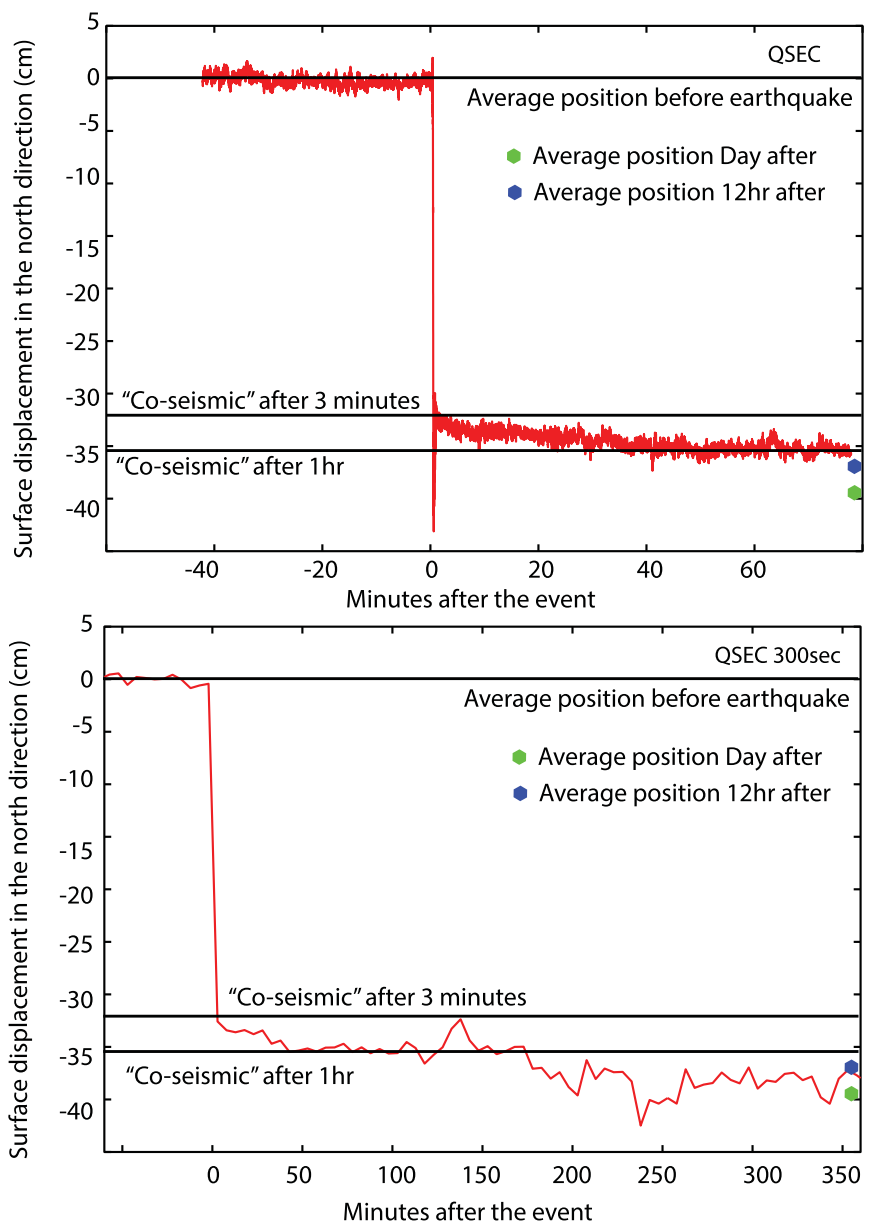

Figure 2. North-South component of high rate time series for QSEC (position computed every $5 \mathrm{~s}$ for the first hour after the earthquake and every $300 \mathrm{~s}$ afterward) with respect to the average position before the earthquake. The green dot represents the "coseismic" displacement based on the average position the day after the earthquake. The blue dot shows the position $12 \mathrm{~h}$ after the earthquake. The two horizontal lines represent the positions computed $3 \mathrm{~min}$ and $1 \mathrm{~h}$ after the earthquake using 2 min averages. All other stations show similar behavior.

\subsection{The 5 September 2012} Coseismic and "Early-Afterslip" Displacement

Coseismic displacement at GPS sites is often reported as the difference at a given station between the average position before an earthquake and the average position at the first available measurement. Even for continuous GPS, the first reported measurement is often the next day. Larson and Miyazaki [2008] showed that for large earthquakes such "coseismic" displacements could be contaminated by fault motion in the few minutes after the end of the seismic event (which we term "early-afterslip"). Comparison of the fault slip associated with the 5 September Nicoya earthquake derived by geodetic data only [Protti et al., 2014] and by a joint inversion of the seismic signal from high rate GPS and seismic data [Yue et al., 2013] indicate that while the estimated main slip areas are very similar, the geodeticonly solution has significantly more slip offshore (Figure 5, insert). Indeed, analysis of the high rate GPS data after the mainshock shows that the GPS stations continue to move for several hours in a direction very similar to the initial slip direction (Figures 2 and 3 ).

Since this deformation is observed on a regional scale, it is unlikely to be related to local or shallow poroelastic deformation, or at least not exclusively.

On the other hand, the very fast response (few hours) suggests that it is unlikely to be related to viscous relaxation. No large thrust aftershocks $(M>5)$ were recorded by the local nor global seismic networks within the first $3 \mathrm{~h}$. Therefore, we suggest that the pattern of surface displacement (Figure 3) observed during the first $3 \mathrm{~h}$ is dominated by aseismic afterslip on the main fault plane. With this assumption, we can invert for slip on the fault that would produce the observed surface displacement.

The fault surface is derived by interpolating and regridding the slab interface provided by DeShon et al. [2006] on a regular grid. We regrid the slab interface using patches with dimensions of $15 \mathrm{~km}$ along strike and $20 \mathrm{~km}$ downdip, based on an analysis of model resolution. Since the DeShon et al. [2006] slab interface is defined only for the region underneath the Nicoya Peninsula, we extend the northwestern and southeastern sides assuming the same geometry.

For each GPS station-fault patch pair, two Green's functions were computed, for unit slip along strike and downdip using the formulation of Okada [1992]. The two components of slip for each patch were then calculated using the Stark and Parker [1995] bounded variables least squares method (BVLS) with Tikhonov regularization, using the algorithm described by Aster et al. [2005]. Negative slip was not allowed in the downdip direction, while no constraint was imposed on along strike slip. The regularization constant was chosen taking the value that maximizes smoothing while minimizing the residual (e.g., Figure 4), such that the residuals are not significantly smaller than the uncertainties of the surface observations. 

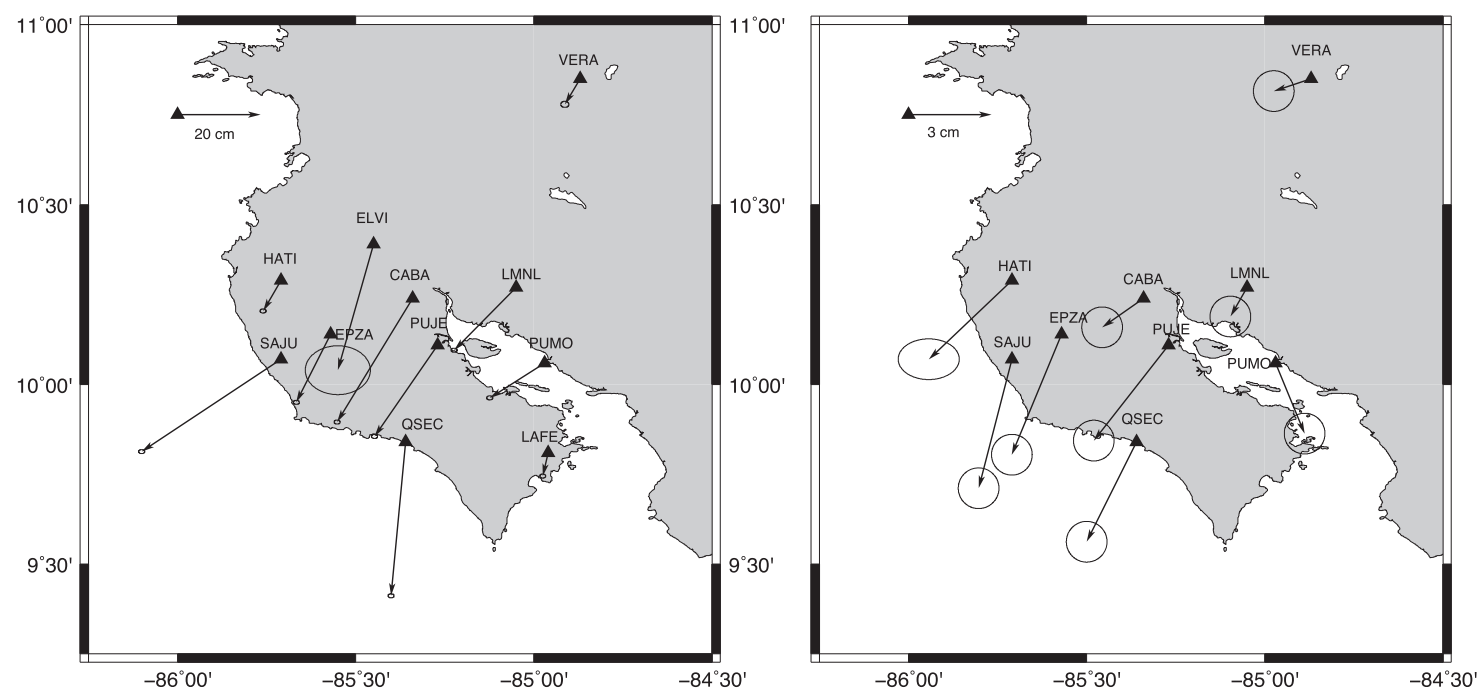

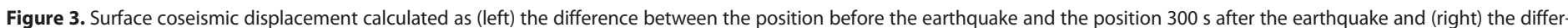
ence between the position $300 \mathrm{~s}$ after the earthquake and the position the next day. Open triangles correspond to stations that did not record at high rate in the hours after the mainshock. Note the change in scale.

The coseismic slip pattern on the plate interface was computed from the complete set of surface displacements observed between the day before and the day after the mainshock using the inversion techniques described above, and is very similar to those presented by Protti et al. [2014] and Dixon et al. [2014]. The fact that we recover similar slip patterns with very different inversion methods and a different description of the slab interface suggests that the computed slip estimates in these studies are robust.

Unfortunately, not all stations recorded at high rate and/or for the full day on 5 September 2012. In particular, the lack of data from IND1 and GRZA, two coastal stations near the center of the peninsula, reduces our offshore resolution.

Figure 5 shows the fault slip computed using the observed displacement between the day before and day after, using just the subset of stations that recorded at high rate. While the pattern of the slip on the fault underneath the peninsula is very similar to the one computed using the full dataset, we obtain significantly less offshore slip. The mainshock coseismic slip estimated with the subset of stations that recorded at high

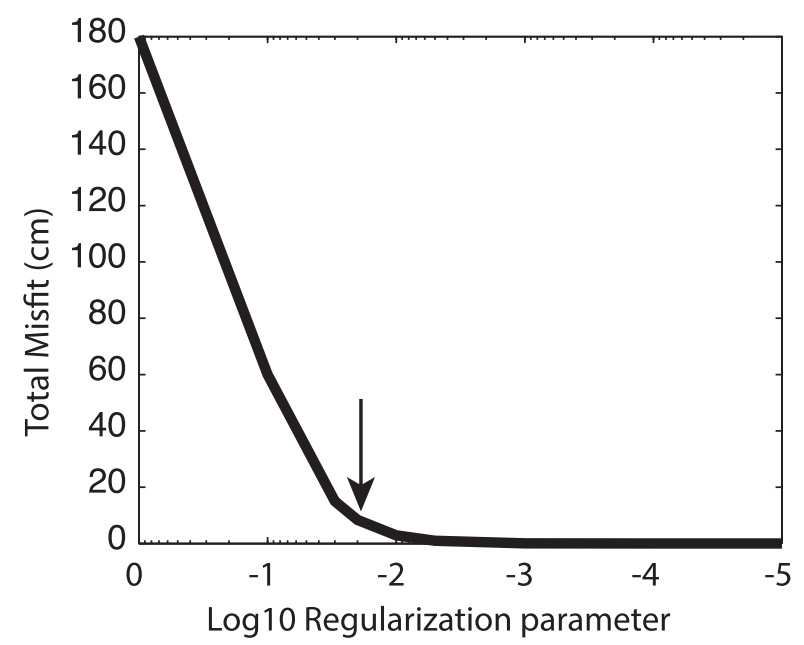

Figure 4. Total misfit of the solution for the inversion of fault slip versus the regularization parameter used to invert the data set in Figure 3 (larger numbers correspond to higher smoothing). The arrow indicates the value used for the inversion shown in Figure 5. rate is somewhat smaller than other results, independent of the smoothing constraints applied, with an effective geodetic magnitude of 7.5 (compared to 7.6 from seismic data or the full geodetic data set).

When we invert for slip using the surface displacement between the position of each station $300 \mathrm{~s}$ and $3 \mathrm{~h}$ after the earthquake, we observe a significant amount of slip offshore (Figure 6), suggesting updip and southwest migration of slip. This earlyafterslip is migrating toward regions previously identified as areas of offshore Slow Slip Events (SSE) [Outerbridge et al., 2010; Jiang et al., 2012; Dixon et al., 2014; Walter et al., 2013]. Although the high-rate network resolution in some areas of SSE is not high, our results suggest that the region of earlyafterslip is limited by the SSE regions (red line in Figure 6). 


\section{QAGU Geochemistry, Geophysics, Geosystems}

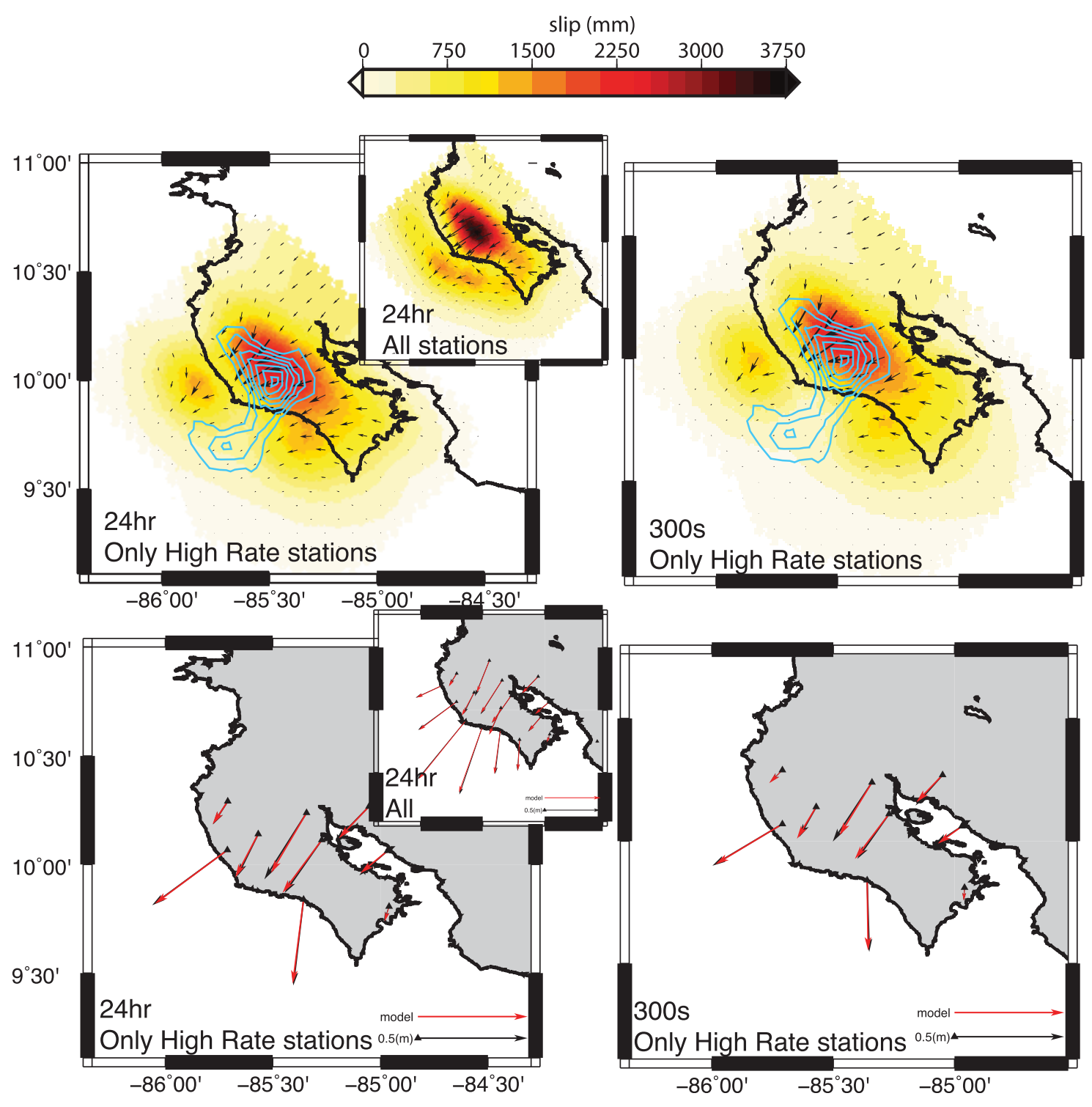

Figure 5. Coseismic fault slip and surface displacement (black = observed, red = modeled) using different subsets of stations and time intervals for the evaluation of surface displace-

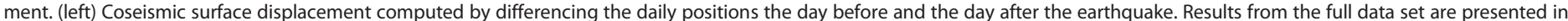

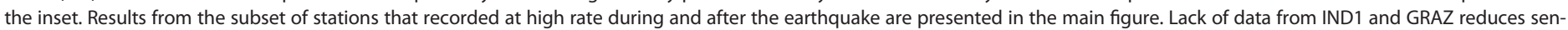

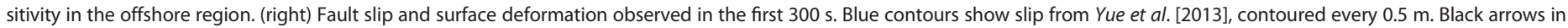
the fault slip maps indicate direction of slip.

\subsection{The 24 October 2012 Aftershock}

On 24 October 2012, the largest aftershock struck the area, an $M_{w} 6.5$ event located near the center of the southwest coast of the peninsula. The event is clearly visible in all the time series and a coseismic displacement can be computed from the geodetic data. We compute the coseismic displacement as the difference of average positions between the day before and the day after the event (data noise does not allow finer time resolution).

Figure 7 shows the observed surface displacement and the calculated coseismic slip on the fault plane using the same methods described above for the mainshock. The estimated geodetic magnitude is 6.6, larger than the seismic magnitude (6.5), suggesting that early-afterslip occurs also with this event as well and is captured by the geodetic data. The slip on the fault seems to fall in the gap between the two slip patches described in the seismic analysis of Yue et al. [2013]. Furthermore, the fault slip seems to overlap with at least half of the area of strong coupling that did not rupture during the 5 September event 


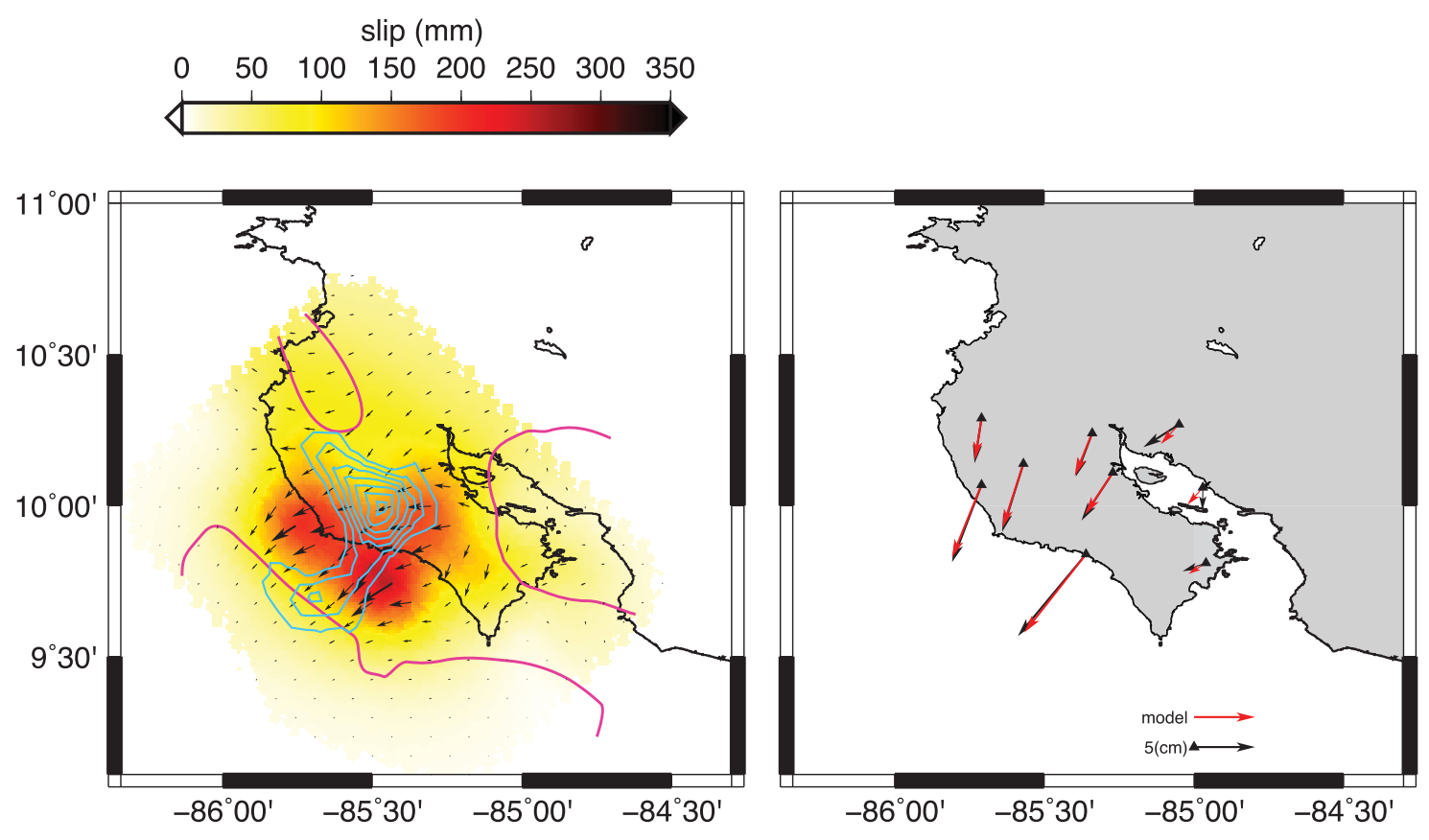

Figure 6. Afterslip during the first $3 \mathrm{~h}$ after the mainshock. Note the different scale of arrow and colorbar with respect to the two previous figures. For reference, the slip inferred from Yue et al. [2013] is shown as blue contours. Cumulative slip of $1 \mathrm{~m}$ from SSEs from Dixon et al. [2014] indicated by the red line. The afterslip is mainly offshore, updip and southwest of the main rupture but limited by the region of SSEs. Given reduced sensitivity in the offshore region, the offshore slip should be interpreted as a lower limit. The main rupture where the resolution is good shows very little displacement.

identified by Protti et al. [2014] (white line in their Figure 4b and green lines in Figure 7 of this paper), though that area experienced significant aftershock seismicity (Figure 1 of Protti et al. [2014] and Figure 13 of this paper). Unfortunately, this aftershock seems to be located in the region where the inversion for early-afterslip has low resolution.

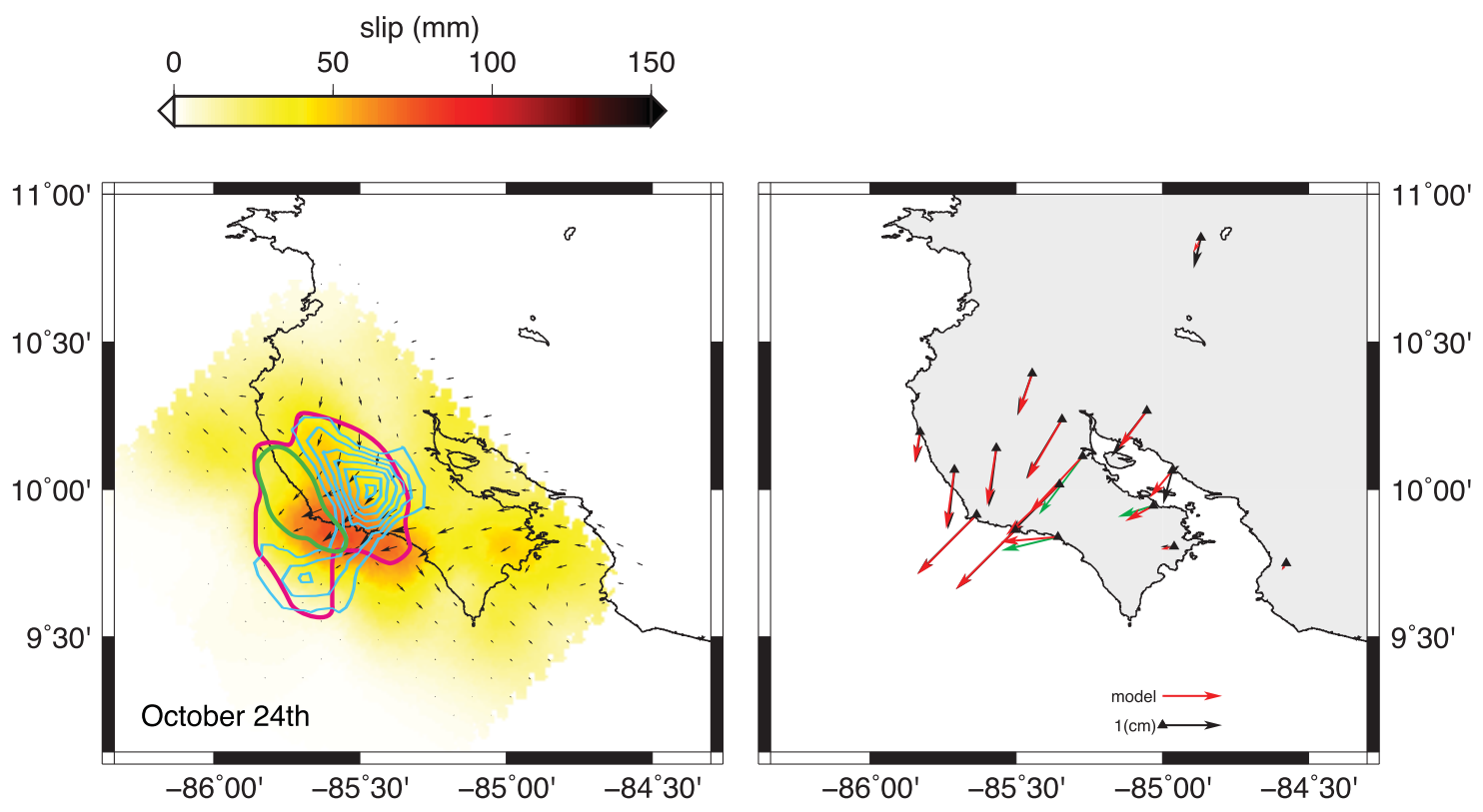

Figure 7. (left) Fault slip and (right) coseismic displacement (black is data, red is model, note overlap at most stations) for the 24 October 2012 aftershock. In left figure, blue contours

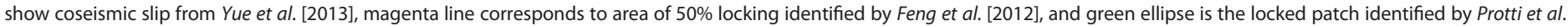

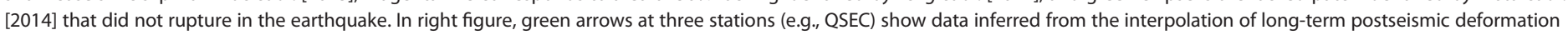
(see text) and are not used in the inversion. 


\section{QAGU Geochemistry, Geophysics, Geosystems}
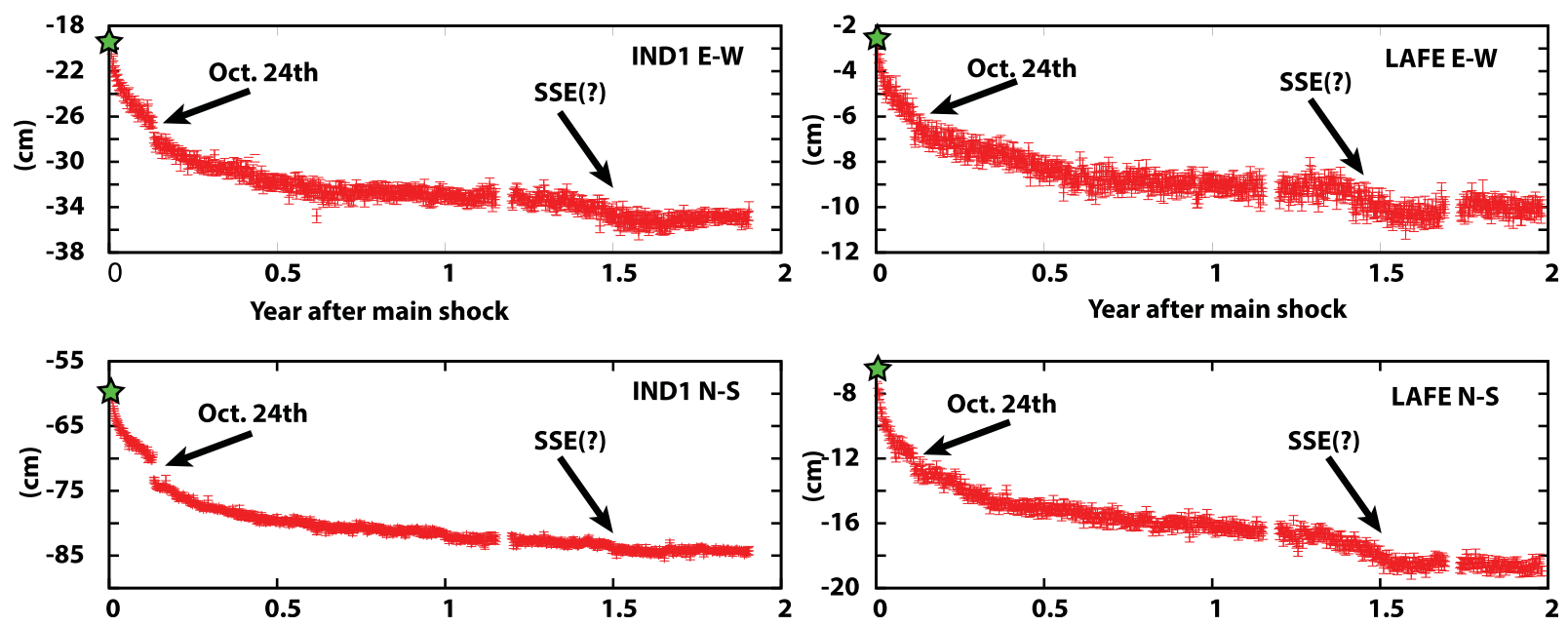

Figure 8. East-West and North-South components of the postseismic displacement for stations IND1 and LAFE. The stars represent the position on 6 September relative to the average

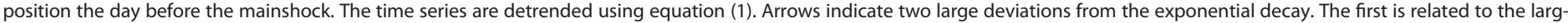
est aftershock, the second (1.4 years after the event) is a possible SSE.

\subsection{Postseismic Deformation}

Following the mainshock of 5 September, all the stations within the network show very strong postseismic signals. As expected, this signal decreases very quickly during the first few days and gradually slows with time. The exponential decay of the postseismic signal is significantly altered by two main events: the aftershock of 24 October described above and a slow perturbation present in all the stations of the network around February 2014 (1.4 years after the event, Figures 8 and 9). This late perturbation has a very similar behavior to previously observed Slow Slip Events [Outerbridge et al., 2010; Jiang et al., 2012]. Although more work is needed to characterize the SSE of February 2014, we note that the displacement time series have characteristics similar to the 2007 SSE.

After we detrend the time series to eliminate the effects of interseismic deformation, the residual time series representing postseismic deformation can be modeled following an exponential decay of the form:

$$
u_{i}\left(t_{j}\right)=b+a\left(1-e^{\frac{t_{j}-t_{0}}{\tau}}\right)
$$

where $\mathrm{u}_{\mathrm{i}}\left(\mathrm{t}_{\mathrm{j}}\right)$ corresponds to the displacement in the i direction at the time $\mathrm{t}_{\mathrm{j}}, b$ corresponds to the coseismic displacement of the mainshock at the time $T_{0}, a$ is the amplitude of the postseismic signal, and $\tau$ is a relaxation time.

Using the multibranch nonlinear least squares Marquardt-Levenberg algorithm as implemented by gnuplot 4.6, we fit the time series using equation (1).

An analysis of the time series indicates the presence of different relaxation times, indicating either the presence of a process that is time dependent (for example, viscous relaxation of a nonlinear body [e.g., Freed and Bürgmann, 2004; Freed et al., 2006a, 2006b], or multilayer viscoelastic body [e.g., Riva and Govers, 2009]) and/or the presence of multiple processes.

The initial period after the earthquake exhibits a very fast relaxation of the order of days. A combination of relaxation times of order a few months or less, and a longer relaxation time of order a few hundred days, is necessary to explain the behavior of the remaining time series over the first 2 years of postseismic motion.

Traditionally, postseismic deformation has been modeled as an exponential process to represent poroelastic and viscoelastic behavior, and/or a logarithmic process to represent afterslip [e.g., Freed et al., 2006a; Hu et al., 2014]. However, the physics of these processes is not completely understood, and there is no fundamental reason requiring either model. For simplicity and to improve the stability of the inversion, we modeled all the time series as linear combination of multiple exponential functions with one to several characteristic relaxation times. An $F$ test showed improved fit going from one to two relaxation times (significant at the $99 \%$ confidence level) 

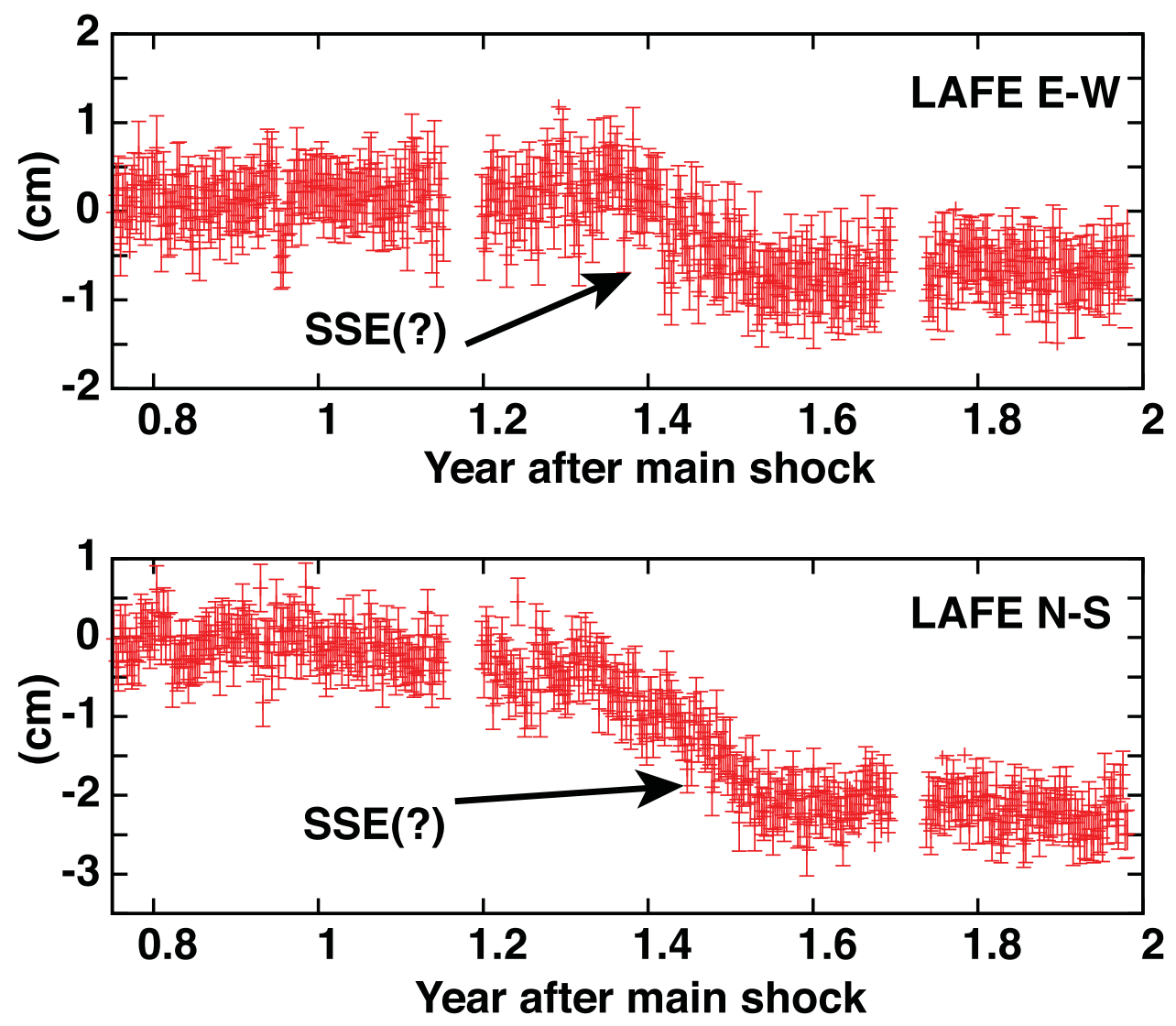

Figure 9. Enlarged plot of the time series shown in Figure 8 during the period of a possible SSE. Both shape (duration time) and amplitude (displacement) are very similar to events identified by Jiang et al. [2012] as Slow Slip Events.

and is further improved (significant at better than 95\% confidence) using three relaxation times. Using more than three relaxation times does not significantly improve the model fit.

We thus solved for a linear combination of three equations (1), with three parameters $a$, and three parameters $\tau$. The final equation is

$$
u_{i}\left(t_{j}\right)=b+a_{1}\left(1-e^{\frac{t_{j}-T_{0}}{\tau_{1}}}\right)+a_{2}\left(1-e^{\frac{t_{j}-T_{0}}{\tau_{2}}}\right)+a_{3}\left(1-e^{\frac{t_{j}-T_{0}}{\tau_{3}}}\right)+c H\left(t_{j}-T_{1}\right)
$$

where we added the Heaviside function $H(t)$ to account for the coseismic displacement (c) associated with the earthquake of 24 October $\left(T_{1}\right)$.

Assuming that relaxation times, $\tau$, represent parameters related to the processes causing the postseismic signal rather than a site-specific parameter, we tried to identify relaxation times that can simultaneously fit all the displacement components for all of the stations. In order to produce a more stable solution, we inverted data from stations with time series that are at least $75 \%$ complete, have data in the first 10 days after the mainshock, and data around 24 October (the time of the large aftershock). To avoid complications with the possible SSE in February 2014, we limit our time series fit to 1.4 years after 5 September. Figure 10 provides the time series and best fit solutions of equation (2) for the seven stations that satisfy the above conditions.

The best solution provides three relaxation times of 7 days, 70 days, and 420 days, with reduced chi square of 1.54 and a WRMS of $4.3 \mathrm{~mm}$. The good fit suggests that the assumption that the relaxation times represent processes affecting all stations is reasonable. A Monte Carlo search for the best relaxation times indicate that, within 3 sigma, the short relaxation time must be between 3 and 23 days; the intermediate relaxation time must be between 45 and 120 days; and the long relaxation time must be longer than 390 days (due to the short time series we cannot constrain the upper bound). 


\section{QAGU Geochemistry, Geophysics, Geosystems}
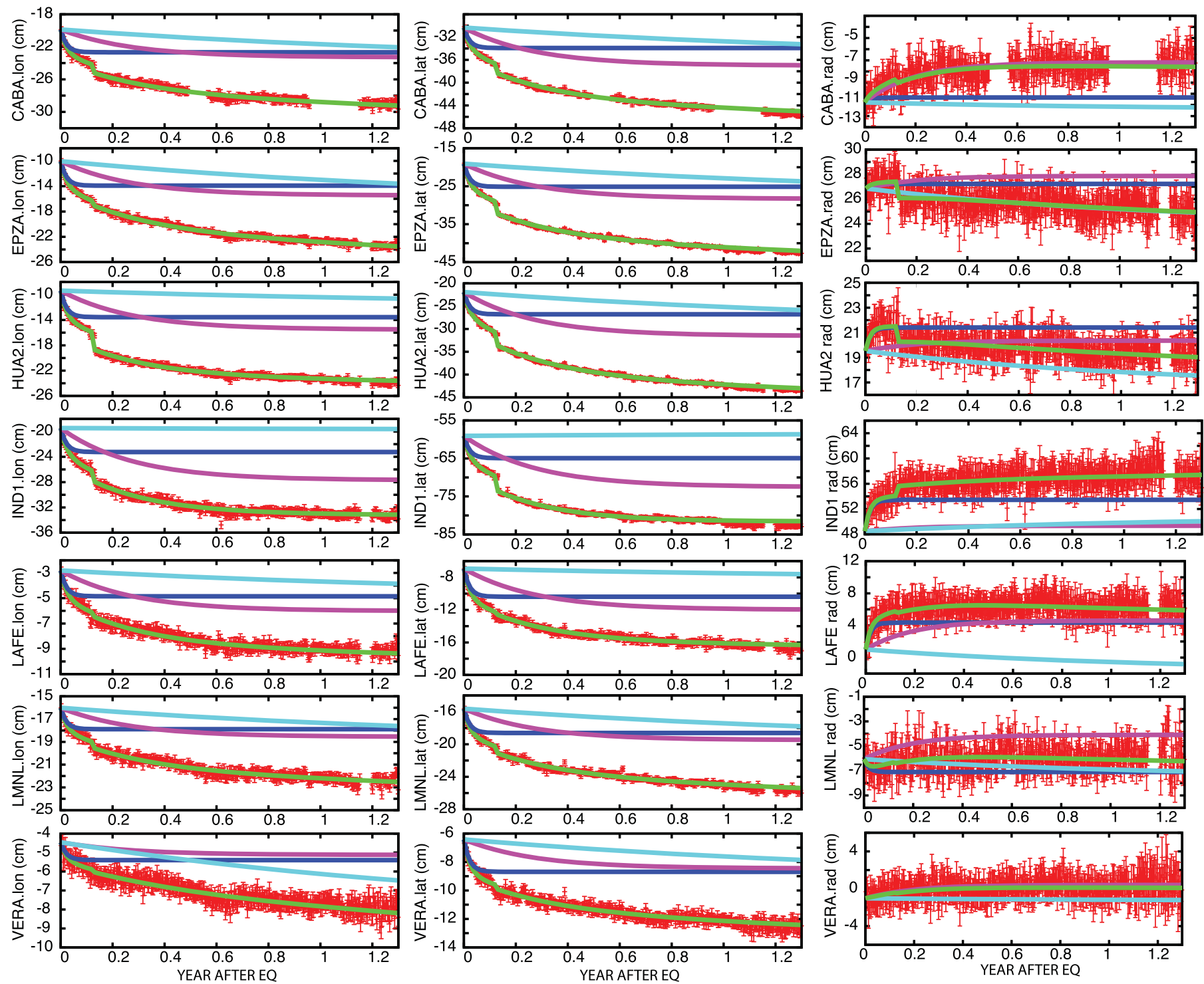

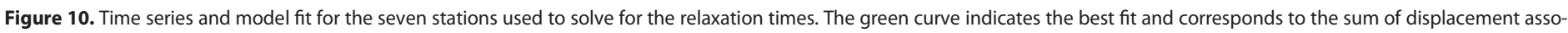
ciated with the main aftershock of 24 October and the displacement associated with three relaxation times (blue, 7 days; magenta, 70 days; cyan, 420 days).

In order to validate our model, we use the computed relaxation time and equation (2) to estimate the coseismic displacement associated with the 24 October aftershock for stations that did not collect data in that period. The green arrows in Figure 7 represent the computed estimated displacements. A comparison with the displacement at these sites derived from the fault slip calculated in the previous paragraph (fault slip map in Figure 7) shows good agreement.

\section{Discussion}

It is difficult to link specific processes with specific relaxation times for postseismic motion: there can be a wide range of relaxation times consistent with a specific process, and it is likely that the processes overlap in time, perhaps operating simultaneously for a significant period [e.g., Montesi, 2004; Barbot and Fialko, 2010]. In the following discussion, we make some inferences concerning dominant processes that are consistent with some other studies of postseismic motion, recognizing the nonuniqueness of these inferences. 


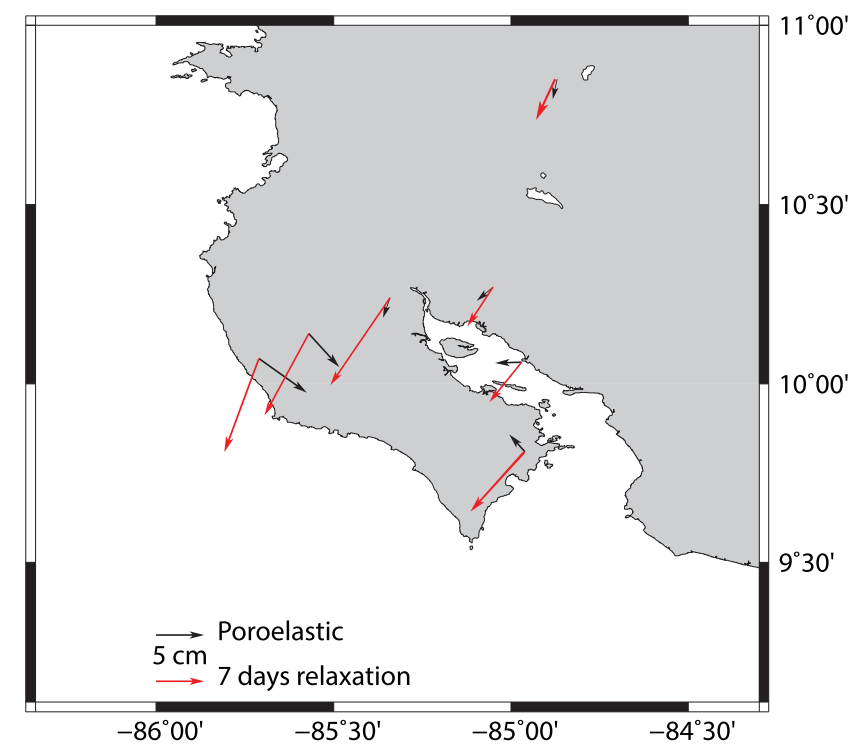

Figure 11. Comparison of displacement inferred for the 7 day relaxation time (red arrow, coefficient $a_{1}$ in equation (2)) and poroelastic deformation obtained calculated by differentiating the surface deformation derived by the fault slip model of Figure 5 for the case of Poisson's ratio equal to 0.34 (undrained) and 0.25 (drained) [Hu et al., 2014]. The poroelastic deformation thus may have an influence on the observed surface deformation field but it cannot be the primary source of deformation. et al., 2014].

It is possible to estimate an upper limit for poroelastic deformation for the 2012 Costa Rica earthquake by differentiating the surface deformation induced by the earthquake (Figure 5) for the case of undrained and drained Poisson's ratio [e.g., Jonsson et al., 2003; Hu et al., 2014]. The results (Figure 11) indicate that the observed deformation is much larger than what would be expected for purely poroelastic deformation. Thus, the poroelastic deformation may influence the observed surface deformation signal (in particular early after the earthquake) but it is not the primary source of deformation. Since poroelastic deformation represents only a small amount of the total deformation field and since it is often associated with relaxation times of the order of days to few tens of days [e.g., Peltzer et al., 1996, 1998; Jonsson et al., 2003], it is likely that it does not significantly impact displacements associated with our intermediate time scale. Thus, we assume that the 70 day relaxation time corresponds to afterslip and the coefficient $a_{2}$ can then be simply interpreted as the amount of afterslip (magenta lines in Figure 10 and arrow on the right map in Figure 12).

The fast decay during the first few days after the main event is more difficult to interpret During this period, afterslip is presumably combined with more diffuse processes such as poroelastic relaxation [e.g., Peltzer et al., 1996, 1998; Jonsson et al., 2003], overriding the subtle signal associated with intraplate deformation. A SSE that was occurring at the time of the mainshock [Dixon et al., 2014] may further complicate the signal. Unfortunately, many of these processes are poorly constrained (for example, to our knowledge, there are no available water well data that could be used to describe poroelastic effects, their relaxation time and duration). Deformation associated with the fast relaxation time therefore needs to be interpreted with caution. It is possible that afterslip with two different time constants ( $\sim 7$ and $\sim 70$ days) is responsible for generating the surface deformation patterns observed in the first few months following the mainshock. It is highly likely that the 7 day relaxation time represents some combination of afterslip and additional processes, such as poroelastic deformation or off-fault deformation (in effect, afterslip on small upper crustal faults). For these reasons, we do not include deformation associated with the 7 day relaxation in our estimation of the total afterslip (implicitly providing a lower limit for the full fault afterslip). In the next section, we compare our estimated postseismic slip patterns with the distribution of interplate aftershocks to help guide our interpretation of the short and intermediate relaxation time deformation. 


\section{QAGU Geochemistry, Geophysics, Geosystems}

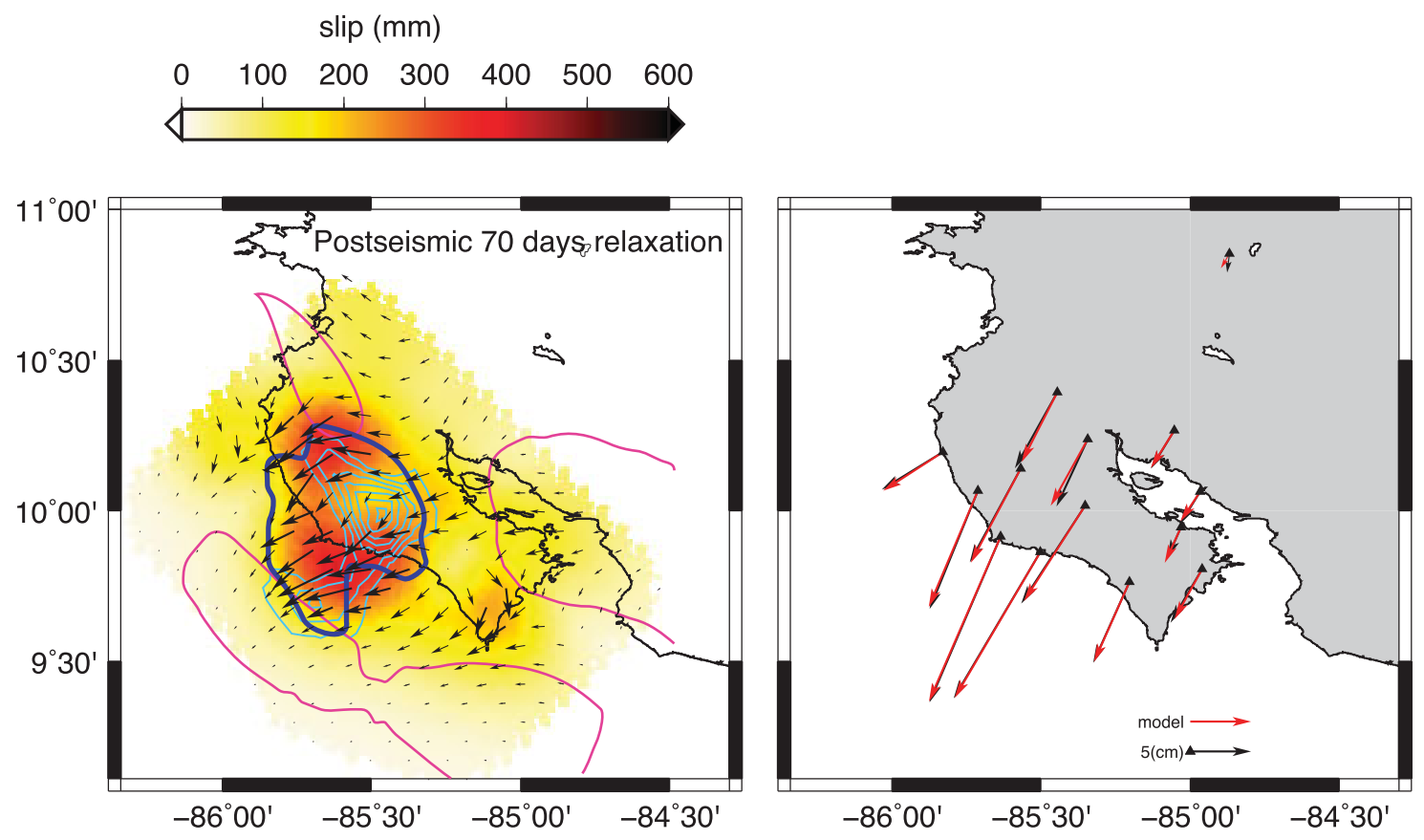

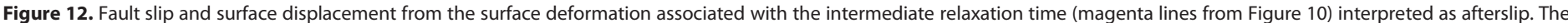
red line indicates $1 \mathrm{~m}$ of cumulative slow slip before the earthquake [Dixon et al. 2014]. The thick black line corresponds to areas with interseismic locking higher than 50\% [Feng et al., 2012].

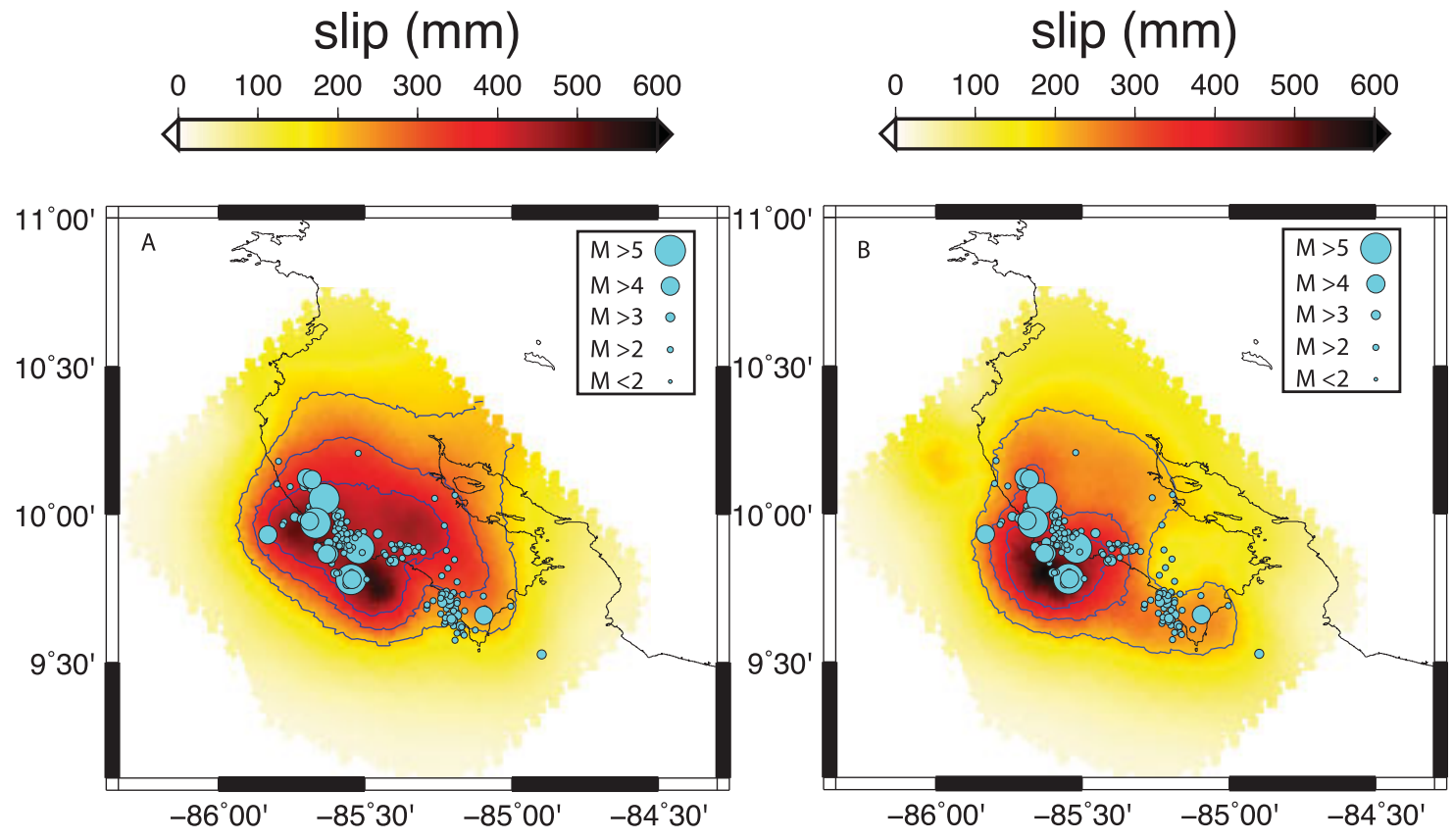

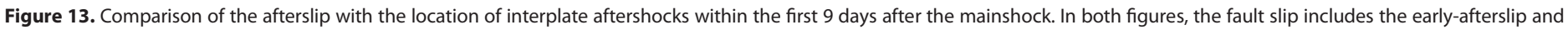
the subsequent slip for the next 9 days with the 70 day time constant (essentially the sum of the slip from Figure 6 and the amount of slip corresponding to 9 days from the model in Figure 12). Blue contour lines correspond to 200,300 , and $400 \mathrm{~cm}$ of inverted fault slip. Seismicity is scaled according to observed magnitude. (a) The inverted fault slip associated with

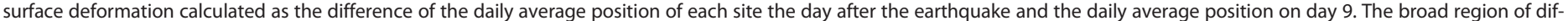
fuse slip in Figure 13a suggests that some of this deformation is not associated with slip on the main fault. (b) The inverted fault slip derived using the $\mathrm{a}_{2}$ term of equation (3) to derive the surface deformation associated with the first 9 days of afterslip. 


\subsection{Geodetic Afterslip Patterns}

As a conservative estimate, we determine the amount of afterslip assuming that it corresponds to the deformation associated with the 70 day relaxation time. The components of surface displacement associated with this process are the coefficients $a_{2}$ from the best fit of each component time series (Figure 12, black arrow on the right). Inverting this surface displacement with the same methodology used for coseismic displacement, we obtain the fault slip associated with this intermediate relaxation time (Figure 12). This afterslip is concentrated close to the main rupture identified by Yue et al. [2013], in particular northwest of the main rupture and updip in an area very similar to the location of the 24 October aftershock. The region is also very close to the area of early-afterslip that occurred in the first hours after the mainshock.

\subsection{Nine-Day Interplate Aftershock Patterns}

Recorded aftershocks following the 5 September earthquake represent a mix of upper crustal (intraplate) earthquakes and events that actually occur on the plate interface (interplate earthquakes). Separating the two is challenging, but is necessary if we wish to compare aftershock seismicity to geodetically determined after slip.

Well-located interplate aftershocks are available for the first nine days after the mainshock. To generate these locations, we start with an automated earthquake catalog generated with the Antelope Seismic Database software that uses an STA/LTA ratio to identify P and S arrivals, associates them and locates events. For the period beginning immediately after the mainshock through 31 December 2012, all phase arrivals and event associations were analyst reviewed and corrected. The corrected phase information was used with SimulPS to relocate all earthquakes in a local three-dimensional velocity model [DeShon et al., 2006]. Many of the $\sim 8400$ relocated earthquakes are intraplate events, occurring within the downgoing slab and in the overlying plate. In order to directly compare geodetically determined afterslip on the plate interface with aftershock activity, we must isolate those events that represent interplate slip on the megathrust. For all events that locate within $10 \mathrm{~km}$ of the plate interface and occur within the first 9 days following the mainshock (aftershock activity is reduced by a factor of 4 after 9 days), we determined first motion focal mechanisms. $P$ wave first motion polarities were identified and used in conjunction with the HASH [Hardebeck and Shearer, 2002] software package to determine the best earthquake focal mechanisms. HASH computes a family of possible focal mechanisms that fit the first motion observations given assumed uncertainties in $P$ wave polarities and velocity structure and returns the most likely mechanism and solution quality. We obtained focal mechanisms for 580 events with approximately half being consistent with underthrusting on the plate interface. Those $\sim 300$ events were then relocated using hypoDD [Waldhauser and Ellsworth, 2000] a double-difference relative relocation technique known to give high-quality absolute locations when station coverage is favorable [Schaff and Waldhauser, 2005]. Figure 13 shows a comparison between these interplate aftershocks and geodetically determined afterslip for the same time period, estimated as described below.

\subsection{Nine-Day Geodetic Afterslip}

We apply two different procedures to estimate the distribution of afterslip for the same time period as the aftershock data, recognizing that processes besides afterslip could contaminate the "raw" displacement data. The first estimate is less restrictive and could include processes other than afterslip. It is calculated by simply differencing the daily average positions at each site between the day after the earthquake and day 9. The second method follows the assumption described in 2.3: the term of equation (2) described by the exponential with amplitude $\mathrm{a}_{2}$ and relaxation time of 70 days represents surface deformation from afterslip. Using this assumption, we can simply calculate the afterslip during the 9 days after the earthquake calculating the value of this exponential at the correct time. For both methods, we add the value of the 9 day afterslip to the early-afterslip, attained within the first $3 \mathrm{~h}$ (Figure 6). These two approaches yield somewhat different results, and are shown in Figure 13, along with the aftershock locations. In particular, we note that the inferred deformation of the first method is much more broad, diffuse on the full plate interface and concentrated in the area with the highest coseismic slip. We thus suggest that the first method is strongly contaminated by off-fault diffuse deformation.

\subsection{Comparison Between Mainshock Slip, Afterslip, and Aftershocks}

Figure 13a shows inferred fault slip derived by taking all surface deformation between day 1 and day 9 . Here a correlation between the amount of slip and seismicity is less obvious. Further, the diffuse high slip 


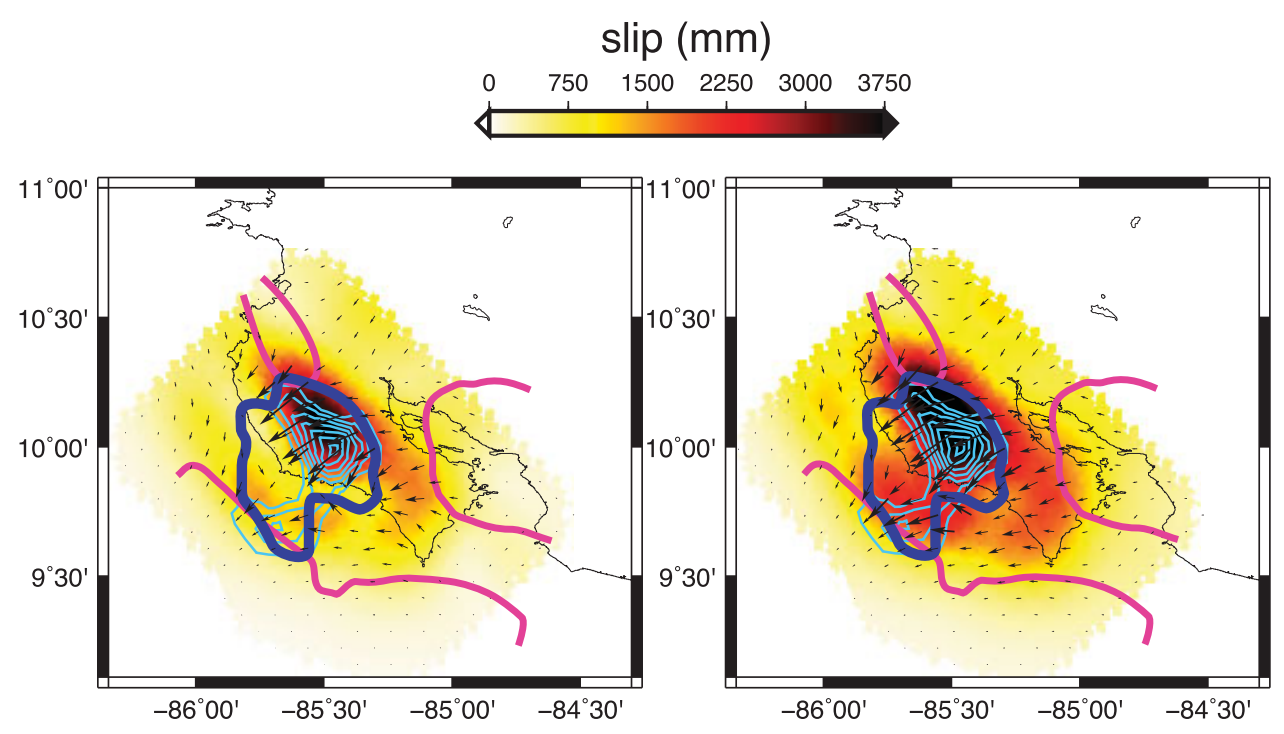

Figure 14. Fault slip. (left) Inverted fault slip from the $24 \mathrm{~h}$ coseismic slip. (right) Sum of $24 \mathrm{~h}$ coseismic slip, the main aftershock of 24 October, and the afterslip from the intermediate relaxation time (total slip). Light blue lines: coseismic slip from Yue et al. [2013]; dark blue line: interseismic locking higher than 50\% from Feng et al. [2012]; red lines contour of $100 \mathrm{~cm}$ of cumulative SSE slip from Dixon et al. [2014].

inferred over a broad region suggests that the observed surface deformation during this period likely reflects processes not localized on the fault plane. In contrast, we see good agreement between interplate aftershock locations and inferred afterslip based on geodetic data and the 70 day relaxation time, giving us confidence that this relaxation time can indeed be associated with fault afterslip.

Although there is a good spatial correlation between geodetically inferred afterslip and the location of aftershocks, the cumulative 9 day aftershock moment $\left(\sim 5.7 \times 10^{17} \mathrm{Nm}\right)$ is at least an order of magnitude lower than the 9 day afterslip moment $\left(\sim 7 \times 10^{18}-1 \times 10^{20} \mathrm{Nm}\right)$. This suggests that afterslip may drive the aftershocks and that surface deformation is not due mainly to aftershocks. The location of the aftershocks at the updip limit of the main rupture is also bounded by a region previously identified as slipping during offshore shallow SSE [Outerbridge et al., 2010; Jiang et al., 2012; Dixon et al., 2014; Walter et al., 2013]. Thus, the shallow patch of preseismic slow slip (10-20 km depth) does not seem to undergo rupture, either during the earthquake, aftershocks, or by afterslip.

We can also compare the integrated displacement associated with the mainshock rupture, the largest aftershock, and afterslip, summing these various components (which we term total slip) for comparison to preevent locking. This may give some idea of unreleased strain, perhaps to be released in a future earthquake, recognizing that there are problems with varying data quality, number of stations available, and inversion assumptions. In order to obviate the problem of the lower number of stations available for inversion of the $300 \mathrm{~s}$ coseismic and early-afterslip, we sum the "coseismic" slip from the $24 \mathrm{~h}$ analysis (insert,

Table 2. Corresponding Seismic Moment From Geodetically Inverted Fault Slip Compared With the Seismic Moment From Global CMT

\begin{tabular}{lcc} 
Event & $\begin{array}{c}\text { Geodetic Moment } \\
(\mathrm{N} \mathrm{m})\end{array}$ & $\begin{array}{c}\text { Corresponding } \\
\mathrm{M}_{\mathrm{w}}\end{array}$ \\
\hline 24 $\mathrm{h}$ "coseismic" & $3.7 \times 10^{20}$ & 7.7 \\
Early-afterslip 300 s-3 h & $3.9 \times 10^{19}$ & 6.9 \\
Coseismic 300 s & $3.3 \times 10^{20}$ & 7.6 \\
24 October aftershock & $8.5 \times 10^{18}$ & 6.6 \\
Afterslip ( $\tau=70$ days) & $6.9 \times 10^{19}$ & 7.2 \\
CMT 5 September & $3.1 \times 10^{20}$ & 7.6 \\
CMT 24 October & $5.3 \times 10^{18}$ & 6.5 \\
10 days aftershock & $5.65 \times 10^{17}$ & \\
\multicolumn{1}{c}{ seismic moment } & & \\
\hline
\end{tabular}
Figure 5 and Figure 14, right) with the fault slip from the main aftershock (Figure 7) and the afterslip from the intermediate relaxation time (Figure 12). The computed fault slip from these three components (total slip) is shown in Figure 14.

Protti et al. [2014] indicated that the main rupture of the 5 September earthquake was located in the area where the fault had the highest interseismic coupling, with a significant "missing" region near the coast (white line in Figure 3 of Protti et al. [2014]). A comparison of the total slip since the main event of 5 September with the interseismic 
coupling from Feng et al. [2012] indicates that the earthquake and its aftermath have probably released a significant amount of the slip deficit that had accumulated prior to 2012.

While afterslip seems to concentrate mainly in the area surrounding the main rupture, some slip within the area of the main rupture is also required to fit the surface observations. A similar pattern was observed by Johnson et al. [2012] for the Tohoku-oki earthquake.

Computation of seismic moment for the different phases of the earthquake shows that a significant amount of elastic energy is released as afterslip (Table 2). Slip released by preearthquake SSEs is also significant [Dixon et al., 2014]. It has long been noted that central America tends to have earthquakes that are large (up to magnitude 8) but not great (magnitude 9 or above) [McNally and Minster, 1981; Pacheco and Skyes, 1992; Pacheco et al., 1993; Scholz and Campos, 2012]. Assuming the 2012 Nicoya earthquake is typical of central American earthquakes, a combination of significant preearthquake slow slip and postearthquake afterslip may be the explanation.

\section{Conclusions}

The postseismic signal after the megathrust earthquake of 5 September 2012 in the Nicoya Peninsula of Costa Rica was well recorded, and involved a complex set of processes acting on multiple time scales. During the first few hours after the mainshock, fast aseismic afterslip seems to be localized on the interplate fault plane. This early-afterslip is mainly concentrated around the main seismic rupture and seems to migrate updip.

After the early-afterslip period, multiple processes relaxing at different time scales affect surface deformation. During the first week after the mainshock, surface deformation includes a fast relaxation process or processes that may not be localized on the fault, and could include poroelastic deformation or motion on upper-crustal faults These diffuse processes obscure fault behavior during the first week. Our estimate of afterslip does not include this time period and is a lower bound. On the other hand, the good correlation of the fault plane seismicity during the first 9 days and a component of deformation characterized by a relaxation time of $\sim 70$ days suggest that fault plane slip dominates other processes in the first few months following the earthquake.

A longer relaxation time likely reflecting viscoelastic relaxation of the lower crust and upper mantle is superimposed on the afterslip signal. Longer observation time will be required to characterize this process.

From surface deformation measurements alone, it is not possible to distinguish whether early-afterslip is a separate process from the afterslip affecting the fault in the following weeks. The integrated fault slip from the mainshock, early-afterslip, longer-term afterslip, aftershocks, and a slow slip event releases a significant fraction of the interseismic strain that had accumulated during the prior 62 year interseismic phase.

Finally, we note that the slip regions for afterslip and shallow SSEs that occurred prior to the 2012 earthquake have very little overlap. This suggests that frictional properties on their respective plate interface regions, or the processes involved in the two slip mechanisms, are substantially different.

Acknowledgments

All the data processed for this paper are publicly available at the UNAVCO archive at the doi number described in Table 1. The processed time series can be requested from the corresponding author (rocco@usf.edu). The authors would like to thank the Editor and two anonymous reviewers for constructive comments that significantly improved the paper. The data analyzed for this paper were generated through the support of NSF/EAR 1345100 to T.H.D. S.Y.S. acknowledges support from NSF/ EAR1321550.

\section{References}

Aster, R. C., B. Borchers, and C. H. Thurber (2005), Parameter Estimation and Inverse Problems, pp. 301, Elsevier, Oxford, U. K. Barbot, S., and Y. Fialko (2010), A unified continuum rapresentation of post-seismic relaxation mechanisms: Semi analytic model of afterslip, poroelastic rebound and viscoelastic flow, Geophys. J. Int., 182(3), 1124-1140.

Beroza, G. C., and S. Ide (2011), Slow earthquakes and nonvolcanic tremor, Annu. Rev. Earth Planet. Sci., 39(1), 271-296.

Bertiger, W., S. D. Desai, B. Haines, N. Harvey, A. W. Moore, S. Owen, and J. P. Weiss (2010), Single receiver phase ambiguity resolution with GPS data, J. Geod., 84(5), 327-337.

Boehm, J., B. Werl, and H. Schuh (2006), Troposphere mapping functions for GPS and very long baseline interferometry from European Centre for Medium-Range Weather forecasts operational analysis data, J. Geophys. Res., 111, B02406, doi:10.1029/2005JB003629.

Brodsky, E. E., and J. Mori (2007), Creep events slip less than ordinary earthquakes, Geophys. Res. Lett., 34, L16309, doi:10.1029/ 2007 GL030917.

Bürgmann, R., and G. Dresen (2008), Rheology of the lower crust and upper mantle: Evidence from rock mechanics, geodesy, and field observations, Annu. Rev. Earth Planet. Sci., 36, 531-567, doi:10.1146/annurev.earth.36031207.124326.

Chacón-Barrantes, S. E., and M. Protti (2011), Modeling a tsunami from the Nicoya, Costa Rica, seismic gap and its potential impact in Puntarenas, J. South Am. Earth Sci., 31, 372-382.

Currie, C. A., and R. D. Hyndman (2006), The thermal structure of subduction zone back arcs, J. Geophys. Res., 111, B08404, doi:10.1029/ 2005JB004024. 
DeMets, C. (2001), A new estimate for present day Cocos \& Caribbean Plate motion: Implications for slip along the Central American Volcanic Arc, Geophys. Res. Lett., 28(21), 4043-4046.

DeMets, C., R. G. Gordon, and D. F. Argus (2010), Geologically current plate motions, Geophys. J. Int., 181(1), 1-80, doi:10.1111/j.1365246X.2009.04491.X.

DeShon, H. R., S. Y. Schwartz, A. V. Newman, V. Gonzales, M. Protti, L. M. Dorman, T. H. Dixon, D. E. Sampson, and E. R. Flueh (2006), Seismogenic zone structure beneath the Nicoya Peninsula, Costa Rica, from three dimensional local earthquake P-and S-wave tomography, Geophys. J. Int., 164, 109-124, doi:10.1111/j.1365-246X.2005.02809.x.

Dixon, J. E., T. H. Dixon, D. R. Bell, and R. Malservisi (2004), Lateral variation in the upper mantle viscosity: Role of water, Earth Planet. Sci. Lett., 222(2), 451-467, doi:10.1016/j.epsl.2004.03.022.

Dixon, T. H. (1993), GPS measurement of relative motion of the Cocos and Caribbean plates and strain accumulation across the Middle America trench, Geophys. Res. Lett., 20(20), 2167-2170.

Dixon, T. H., Y. Jiang, R. Malservisi, R. McCaffrey, N. Voss, M. Protti, and V. Gonzalez (2014), Earthquake and tsunami forecasts: Relation of slow slip events to subsequent earthquake rupture, Proc. Natl. Acad. Sci. U. S. A., 111, 17,039-17,044, doi:10.1073/pnas.1412299111.

Feng, L., A. V. Newman, M. Protti, V. González, Y. Jiang, and T. H. Dixon (2012), Active deformation near the Nicoya Peninsula, northwestern Costa Rica, between 1996 and 2010: Interseismic megathrust coupling, J. Geophys. Res., 117, B06407, doi:10.1029/2012JB009230.

Freed, A. M., and R. Bürgmann (2004), Evidence of power-law flow in the Mojave desert mantle, Nature, 430, 548-551.

Freed, A. M., R. Bürgmann, E. Calais, J. Freymueller, and S. Hreinsdottir (2006a), Implications of deformation following the 2002 Denali, Alaska, earthquake for postseismic relaxation processes and lithospheric rheology, J. Geophys. Res., 111, B01401, doi:10.1029/ 2005JB003894.

Freed, A. M., R. Bürgmann, E. Calais, and J. Freymueller (2006b), Stress-dependent pow-law flow in the upper mantle following the 2002 Denali, Alaska, earthquake, Earth Planet. Sci. Lett., 252, 481-489.

Fung, Y.C., and P. Tong (2001), Classical and Computational Solid Mechanics, Adv. Ser. Eng. Sci., vol. 1, World Sci., Singapore.

Hardebeck, J. L., and P. M. Shearer (2002), A new method for determining first-motion focal mechanisms, Bull. Seismol. Soc. Am., 92, $2264-2276$.

Hayes, G. P., D. J. Wald, and R. L. Johnson (2012), Slab1.0: A three-dimensional model of global subduction zone geometries, J. Geophys. Res., 117, B01302, doi:10.1029/2011JB008524.

Helmstetter, A., and B. E. Shaw (2009), Afterslip and aftershocks in the rate-and-state friction law, J. Geophys. Res., 114, B01308, doi:10.1029/ $2007 J B 005077$.

Hu, Y., R. Bürgmann, J. T. Freymueller, P. Benerjee, and K. Wang (2014), Contributions of poroelastic rebound and a weak volcanic arc to the postseismic deformation of the 2011 Tohoku earthquake, Earth Planets Space, 66, 106.

Jiang, Y., S. Wdowinski, T. H. Dixon, M. Hackl, M. Protti, and V. Gonzalez (2012), Slow slip events in Costa Rica detected by continuous GPS observations, 2002-2011, Geochem. Geophys. Geosyst., 13, Q04006, doi:10.1029/2012GC004058.

Johnson, K. M., J. Fukuda, and P. Segall (2012), Challenging the rate-state asperity model: Afterslip following the 2011 M9 Tohoku-oki, Japan, earthquake, Geophys. Res. Lett., 39, L20302, doi:10.1029/2012GL052901.

Jonsson, S., P. Segall, R. Pedersen, and G. Bjornsson (2003), Post-earthquake ground movements correlated to pore-pressure transients, Nature, 424, 179-183.

Kikuchi, M., and H. Kanamori (1995), Source characteristics of the 1992 Nicaragua tsunami earthquake inferred from teleseismic body waves, Pure Appl. Geophys., 144, 441-453.

Larson, K., A. Bilich, and P. Axelrad (2007), Improving the precision of high rate GPS, J. Geophys. Res. 112, B05422, doi:10.1029/ $2006 \mathrm{JB} 004367$.

Larson, K. M., and S. Miyazaki (2008), Resolving static offset from high-rate GPS data: The 2003 Tokachi-oki earthquake, Earth Planets Space, $60,801-808$.

Lyard, F., F. Lefevre, T. Letellier, and O. Francis (2006), Modeling the global ocean tides: Modern insights from FES2004, Ocean Dyn., 56(5-6), 394-415.

Masterlark, T. (2003), Finite element model predictions of static deformation from dislocation sources in a subduction zone: Sensitivities to homogeneous, isotropic, Poisson-solid, and half-space assumptions, J. Geophys. Res., 108(B11), 2540, doi:10.1029/2002JB002296.

McNally, K. C., and J. B. Minster (1981), Nonuniform seismic slip rates along the Middle America Trench, J. Geophys. Res., 86(B6), $4949-4959$.

Montesi, L. G. J. (2004), Controls of shear zone rheology and tectonic loading on postseismic creep, J. Geophys. Res., 109, B10404, doi: $10.1029 / 2003 J$ J002925.

Okada, Y. (1992), Internal deformation due to shear and tensile faults in a half-space, Bull. Seismol. Soc. Am., 82, $1018-1040$.

Outerbridge, K. C., T. H. Dixon, S. Y. Schwartz, J. I. Walter, M. Protti, V. Gonzalez, J. Biggs, M. Thorwart, and W. Rabbel (2010), A tremor and slip event on the Cocos-Caribbean subduction zone as measured by a global positioning system (GPS) and seismic network on the Nicoya Peninsula, Costa Rica, J. Geophys. Res., 115, B10408, doi:10.1029/2009JB006845.

Pacheco, J. F., and L. R. Skyes (1992), Seismic moent catalog of large shallow earthquakes, 1900 to 1989, Bull. Seismol. Soc. Am., 82, 13061349.

Pacheco, J. V., L. R. Sykes, and C. H. Scholz (1993), Nature of seismic coupling along simple plate boundaries of the subduction type, J. Geophys. Res., 98(B8), 14,133-14,159.

Peltzer, G., P. Rosen, F. Rogez, and K. Hudnut (1996), Postseismic rebound in fault stepovers caused by pore fluid flow, Science, 273(5279), 1202-1204, doi:10.1126/science.273.5279.1202.

Peltzer, G., P. Rosen, F. Rogez, and K. Hudnut (1998), Poro-elastic rebound along the landers 1992 earthquake surface rupture, J. Geophys. Res., 103(B12), 30,131-30,145.

Perfettini, H., and J. P. Avouac (2004), Postseismic relaxation driven by brittle creep: A possible mechanism to reconcile geodetic measurements and the decay rate of aftershocks, application to the Chi-Chi earthquake, Taiwan, J. Geophys. Res., 109, B02304, doi:10.1029/ $2003 \mathrm{JB} 002488$.

Perfettini, H., and J. P. Avouac (2007), Modeling afterslip and aftershocks following the 1992 Landers earthquake, J. Geophys. Res., 112, B07409, doi:10.1029/2006JB004399.

Protti, M., et al. (1995), The March 25, $1990(\mathrm{Mw}=7.0, \mathrm{ML}=6.8)$, earthquake at the entrance of the Nicoya Gulf, Costa Rica: Its prior activity, foreshocks, aftershocks, and triggered seismicity, J. Geophys. Res., 100(B10), 20,345-20,358, doi:10.1029/94JB03099.

Protti, M., V. González, A. V. Newman, T. H. Dixon, S. Y. Schwartz, J. S. Marshall, L. Feng, J. I. Walter, R. Malservisi, and S. E. Owen (2014), Nicoya earthquake rupture anticipated by GPS measurements of the locked plate interface, Nat. Geosci., 7, 117-121, doi:10.1038/ ngeo2038.

Rebischung, P., J. Griffiths, J. Ray, R. Schmid, X. Collilieux, and B. Garayt (2012), IGS08: The IGS realization of ITRF2008, GPS Solutions, 16, 483-494, doi:10.1007/s10291-011-0248-2. 
Riva, R. E. M., and R. Govers (2009), Relating viscosities from postseismic relaxation to a realistic viscosity structure for the lithosphere, Geophys. J. Int., 176, 614-624.

Satake, K. (1994), Mechanism of the 1992 Nicaragua tsunami earthquake, Geophys. Res. Lett., 21(23), 2519-2522.

Savage, J. C., and J. L. Svarc (1997), Postseismic deformation associated with the $1992 \mathrm{Mw}=7.3$ Landers earthquake, southern California, J. Geophys. Res., 102(B4), 7565-7577.

Schaff, D. P., and F. Waldhauser (2005), Waveform cross-correlation-based differential travel-time measurements at the northern California seismic network, Bull. Seismol. Soc. Am., 95(6), 2446-2461.

Scholz, C. H., and J. Campos (2012), The seismic coupling of subduction zones revisited, J. Geophys. Res., 117, B05310, doi:10.1029/ 2011 JB009003.

Schwartz, S. Y., and J. M. Rokosky (2007), Slow slip events and seismic tremor at circum-Pacific subduction zones, Rev. Geophys., 45 , RG3004, doi:10.1029/2006RG000208.

Stark, P. B., and R. L. Parker (1995), Bounded-variable least-squares: An algorithm and applications, Comput. Stat., 10(1995), $129-129$.

Waldhauser, F., and W. L. Ellsworth (2000), A double-difference earthquake location algorithm: Method and application to the northern Hayward fault, Bull. Sesimol. Soc. Am., 90, 1353-1368.

Walter, J. I., S. Y. Schwartz, M. Protti, and V. Gozales (2013), The synchronous occurrence of shallow tremor and very low frequency earthquakes offshore of the Nicoya Peninsula, Costa Rica, Geophys. Res. Lett., 40, 1517-1522, doi:10.1002/grl.50213.

Yue, H., T. Lay,S. Y. Schwartz, L. Rivera, M. Protti, T. H. Dixon, and S. Owen (2013), The 5 September 2012 Costa Rica Mw 7.6 earthquake rupture process from joint inversion of high-rate GPS, strong-motion, and teleseismic P wave data and its relationship to adjacent plate boundary interface properties, J. Geophys. Res., 118, 5453-5466, doi:10.1002/jgrb.50379.

Zumberge, J. F., M. B. Heflin, D. J. Jefferson, M. M. Watkins, and F. H. Webb (1997), Precise point positioning for the efficient and robust analysis of GPS data from large networks, J. Geophys. Res., 102(B3), 5005-5017. 